\title{
Clinical phenotypes of primary hyperparathyroidism in hospitalized patients who underwent parathyroidectomy
}

\author{
Liubov G Yanevskaya', Tatiana Karonova ${ }^{1,2}$, llya V Sleptsov³, Marina Evgenevna Boriskova², \\ Aluza Ramilevna Bakhtiyarova', Roman A Chernikov³, Karina Aleksandrovna Pogosian', \\ Alena Timurovna Andreeva1', Denis Andreevich Lebedev¹, Elena Nikolaevna Grineva ${ }^{1,2}$ and John P Bilezikian ${ }^{4}$ \\ ${ }^{1}$ Almazov National Medical Research Centre, St. Petersburg, Russia \\ ${ }^{2}$ First Pavlov State Medical University, St. Petersburg, Russia \\ ${ }^{3}$ Saint-Petersburg State University N.I. Pirogov Clinic of High Medical Technologies, St. Petersburg, Russia \\ ${ }^{4}$ College of Physicians and Surgeons, Columbia University, New York, New York, USA
}

Correspondence should be addressed to L G Yanevskaya or T Karonova: fosterthefire@yandex.ru or karonova@mail.ru

\begin{abstract}
Objective: The aim of our study was to investigate the distribution of the PHPT clinical manifestations and biochemical features in patients who underwent parathyroidectomy. Materials and methods: Medical records of 449 patients from three Medical Centers (Saint-Petersburg, Russia), hospitalized during a period from 2011 to 2018, were reviewed. History and anthropometric data, laboratory results (iPTH, total and iCa, phosphorus, ALP, 24-h urinary calcium, 25(OH)D) and imaging data (ultrasonography, scintigraphy, CT/MRI scan, DXA) were analyzed.

Results: Three hundred ninety-four patients were included in the final analysis. Median age was 60 years with $94.2 \%$ being women. Symptomatic disease was evident in 222 (56.4\%) patients, asymptomatic in 172 (43.6\%). Skeletal involvement was more common for women, while frequency of other manifestations did not differ in both genders. There was no difference between symptomatic and asymptomatic patients in age. Serum iPTH level was higher in symptomatic patients (202.9 and $181.0 \mathrm{pg} / \mathrm{mL}, P=0.022$ ). Serum 25(OH)D level was estimated in few patients and negatively correlated with PTH $(r=-0.294, P=0.005)$, iCa $(r=-0.268, P=0.010)$ and total $\mathrm{Ca}(r=-0.284, P=0.014)$ levels. Manifestations of CVD were observed in $67.7 \%$ of cases and affected equally both symptomatic and asymptomatic patients $(70.7$ and $63.4 \%, P=0.076)$. Both age and BMI were higher in patients with CVD, whether or not they were symptomatic (62 and 53 years, $P<0.0001 ; 30.4$ vs $26.0 \mathrm{~kg} / \mathrm{m}^{2}, P<0.0001$, respectively). Conclusions: This experience illustrates that symptomatic phenotype is still the most common form of PHPT.
\end{abstract}
Key Words
- primary hyperparathyroidism
- hypercalcemia
- parathyroid hormone
- vitamin D
- parathyroid gland

\section{Introduction}

Primary hyperparathyroidism (PHPT) is a disease characterized by excessive synthesis and secretion of parathyroid hormone (PTH) from one or more of the four parathyroid glands (1). Most patients present with hypercalcemia though normocalcemic PHPT is now recognized as a frequent phenotype of the disease (2).

The incidence of PHPT varies from 1 to 21 cases per 1000 individuals (3), with aging associated with greater

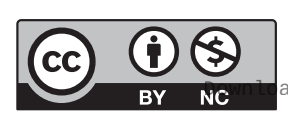

This work is licensed under a Creative Commons Attribution-NonCommercial 4.0 International License. ded from Bioscientifica.com at 04/26/2023 06:45:28AM 
incidence (4). The disease more commonly affects women, and the F:M ratio is 3:1 in North American and Western European population, but PHPT prevalence does not differ by gender under the age of $45(5,6,7,8)$.

Since the 1970s, the clinical presentation of PHPT has gradually changed in many countries from being a symptomatic disorder to an asymptomatic one (1). The reason for this change in presentation among individuals in those countries is the common use of biochemical screening tests that include the serum calcium measurement routinely. As a result, most patients diagnosed with PHPT do not have overt signs of kidney or bone disease, and are thus, termed 'asymptomatic' (9). This change in clinical presentation is relevant for Europe and North America where most published studies describe the asymptomatic form of the disease as the most common $(1,3,6,7,8,9,10)$. Since the 2000 s, yet another PHPT presentation is recognized, namely normal total and ionized calcium concentration with high PTH in the absence of any secondary causes for the elevated PTH level $(2,10,11,12,13)$. The characterization of these three groups of patients with PHPT was acknowledged and defined by the last workshop on the Management of Asymptomatic Primary Hyperparathyroidism in 2014 (13).

Much less is known about the PHPT presentations in Eastern European, former Soviet countries, and in Russia. To the extent that data are available, reports continue to demonstrate that symptomatic PHPT is the more common form of the disease in Russia, accounting for about twothirds of cases $(5,14)$. This study was conducted to determine whether the prevalence of this disease with regard to clinical presentations in Russia has changed since earlier reports.

The aim of this study was to identify the distribution of the major clinical phenotypes of PHPT and their associated biochemical features by retrospectively collecting data for patients, admitted to three medical centers in Saint-Petersburg, Russia.

\section{Materials and methods}

\section{Patients}

We reviewed medical records of 449 PHPT patients 18 years and older living in different regions of Russia and admitted to three Medical Centers in endocrinology and endocrine surgery departments in Saint-Petersburg, Russia between 2011 and 2018. All subjects were in-patients. Seventyfive patients (70 females and 5 males) from the endocrine department of Almazov National Medical Research Center (Almazov Center), 35 patients (33 females and 2 males) from the endocrine and the endocrine surgery departments of First Pavlov State Medical University (Medical University) and 339 patients (315 females and 24 males) from the endocrine surgery department of Saint-Petersburg State University N.I. Pirogov Clinic of High Medical Technologies (Pirogov Clinic). We collected all data from the patients records without having direct contact with them during their hospitalization. Patients with secondary and tertiary hyperparathyroidism were not included.

We analyzed anamnesis of the disease, anthropometric data (weight, height, BMI). Analyzing the history, we tried to determine the duration of the disease. The checkpoint was the earliest (i) imaging data where the formation was found, (ii) the first recorded increase of the serum ionized or total calcium level, (iii) the first case of the fragility fracture, (iv) the first renal colic associated with urolithiasis. The duration was calculated until the last surgery related visit. PHPT was diagnosed by laboratory tests (elevated iPTH, high or normal level of serum total or ionized calcium levels) $(5,13,15)$. Patients who had skeletal manifestations (osteitis fibrosa cystica and fragility fractures), nephrolithiasis or nephrocalcinosis, cholelithiasis, peptic ulcer disease (PUD), pancreatic calcification and erosive lesions of upper gastrointestinal (GI) tract were considered to be symptomatic. Patient without those clinical manifestation was considered to be asymptomatic $(13,15)$.

Out of 449 patients 18 had multiple endocrine neoplasia (MEN), and one had parathyroid carcinoma. These patients were excluded from the final analysis. In addition, 37 patients had normal serum calcium level, one of them had MEN. Serum 25(OH)D level, available only for four patients out of 37 , was in the median range of $22.2 \mathrm{ng} / \mathrm{mL}$ (19.6-25.6). That being said, we could not rule out secondary PHPT in these patients due to lack of data, so we excluded them as well. Hence, 394 patients were included in the final analysis.

The Ethics Committee of Almazov National Medical Research Center, St. Petersburg, Russia approved the study and all procedures were carried out in accordance with the Declaration of Helsinki. Patients provided their consent upon hospitalization for the use of their data in research purposes.
This work is licensed under a Creative Commons Attribution-NonCommercial 4.0 International License. ded from Bioscientifica.com at 04/26/2023 06:45:28AM via free access 


\section{Laboratory and instrumental tests}

Laboratory methods were different depending on the Center. The biochemical parameters (alkaline phosphatase (ALP) (<105 UI/L), 24 h-urinary calcium $(2.5-8.0 \mathrm{mmol} /$ day), creatinine (53.0-97.0 $\mu \mathrm{mol} / \mathrm{L})$, ionized (iCa) and total calcium (Ca) $(2.15-2.65 \mathrm{mmol} / \mathrm{L}$ and $1.11-1.32$ $\mathrm{mmol} / \mathrm{L}$,respectively), and phosphorus (0.81-1.45 $\mathrm{mmol} / \mathrm{L}$ ) levels in Almazov Center and Medical University were measured by autoanalyzer Architect c8000 (Abbott Laboratories). In Pirogov Clinic biochemical parameters were measured by AU 5800 (Beckman Coulter Inc., CA, USA). Intact PTH (iPTH, 15.0-65.0 pg/mL) was assessed in Almazov Center and in Medical University using immunochemiluminescent assay (Architect i2000SR, Abbott Laboratories and Elycsys 2010, Roche-Diagnostics $\mathrm{GmbH})$. In Pirogov Clinic the iPTH was determined by chemiluminescence method (Liaison (Diasorin, Saluggia, VC, Italy and Unicel DXI 800 Access, Beckman Coulter Inc., CA, USA). To convert $\mathrm{pmol} / \mathrm{L}$ to $\mathrm{pg} / \mathrm{mL}$ we divided the value in $\mathrm{pmol} / \mathrm{L}$ by 0.105 . Serum $25(\mathrm{OH}) \mathrm{D}$ level $(30-100 \mathrm{ng} / \mathrm{mL})$ was measured by immunochemiluminescent assay (Architect i2000SR, Abbott Laboratories) in all Centers. The calcium-phosphate product was calculated $\left(<4.44 \mathrm{mmol}^{2} / \mathrm{L}^{2}\right)$. The glomerular filtration rate (GFR) was calculated by MDRD formula. It is noted that not all patients underwent complete biochemical evaluation according to the AAES guideline (13): serum 25(OH)D level was identified only in 92 cases and 24-h urinary calcium level is known only in 64 cases.

Imaging data (neck ultrasonography, sestamibi parathyroid scintigraphy, CT/MRI scan, abdominal ultrasound, dual-energy X-ray absorptiometry (DXA)) available in medical records were analyzed.

\section{Statistical analysis}

Statistical analysis was performed with STATISTICA 10.0 software (StatSoft, Tulsa, OK, USA). Most characteristics demonstrated non-normal distribution, therefore, nonparametric criteria were used. Continuous characteristics of the subgroups were described by medians (Me) and quartiles $(25 ; 75)$. For paired comparisons of quantitative characteristics, the Mann-Whitney $U$-test was used. When comparing more than two groups, the KruskalWallis test with post hoc multiple comparisons was used. Discrete characteristics were compared using the chi-square test (Fisher's exact test was used for binary characteristics).

\section{Results}

The majority of PHPT patients were women (94.2\%). Ranging from 23 to 87 years, the median age was 60 years, with $69.5 \%$ of patients over 55 years old. The age of males and females did not differ ( 55 vs $60, P=0.08$ ). General characteristics of PHPT patients are presented in the Table 1.

Clinical manifestation of PHPT included fragility fractures or osteitis fibrosa cystica, nephrolithiasis or nephrocalcinosis and other associations such as gallstones, peptic ulcer disease (PUD), erosive gastritis and erosive reflux esophagitis (Table 1 ).

Eighty-nine percent of patients underwent ultrasonography and in $94 \%$ of cases the parathyroid adenoma was found. The sestamibi parathyroid scan was positive in $90 \%$ of the 279 patients. Neck CT used less frequently, in only 134 (34.1\%) patients and was positive in $95.5 \%$ of cases. Neck MRI performed only in 14 patients, and was positive in $81.8 \%$ of cases.

Three hundred ninety-three patients $(99.7 \%)$ had at least one criterion for surgery according to the guideline (13): serum total calcium level more than $0.25 \mathrm{mmol} / \mathrm{L}$ above normal range, GRF less than $60 \mathrm{~mL} / \mathrm{min} / 1.73 \mathrm{~m}^{2}$, nephrocalcinosis/nephrolithiasis, DXA T-score less than $-2.5 \mathrm{SD}$, evidence of fragility fractures and age younger 50 .

A total of 387 patients underwent parathyroidectomy. The vast majority had removal of a single adenoma (360 patients; 93.0\%). Multiple adenomas were identified in $20(5.2 \%)$ cases and only seven patients (1.8\%) had hyperplasia of parathyroid glands. Seven patients did not undergo parathyroid surgery: four patients refused, two of them had severe concomitant diseases and one did not have indication for surgical intervention.

Based upon the current guidelines $(13,15)$, patients were divided into two groups; symptomatic patients demonstrated one or more of these clinical manifestations and constituted $56.4 \%$ (222 subjects) of the sample size. Asymptomatic patients had none of these clinical manifestations and constituted $43.6 \%$ of the sample size (Table 2).

The median age of the symptomatic and asymptomatic PHPT patients did not differ (60 and 59 years, respectively, $P=0.36)$. Also, the time between the first clinical or laboratory symptoms and diagnosis was the same in groups.

About half of the patients had low bone mineral density (BMD) and we did not find differences in DXA-based BMD at all three sites in symptomatic and
This work is licensed under a Creative Commons Attribution-NonCommercial 4.0 International License. ded from Bioscientifica.com at 04/26/2023 06:45:28AM 
Table 1 General characteristics of patients with PHPT.

\begin{tabular}{|c|}
\hline Parameters \\
\hline Age, years \\
\hline Age over 55 years, $n(\%)$ \\
\hline Gender: female, n (\%) \\
\hline Male, $n(\%)$ \\
\hline $\mathrm{BMI}, \mathrm{kg} / \mathrm{m}^{2}$ \\
\hline Known duration of PHPT*, years \\
\hline Osteoporosis, $n(\%)$ \\
\hline Fractures, $n(\%)$ \\
\hline Osteitis fibrosa cystica, $n(\%)$ \\
\hline Nephrolithiasis/nephrocalcinosis, $n(\%)$ \\
\hline Gallstone disease, $n(\%)$ \\
\hline Peptic ulcer disease, $n(\%)$ \\
\hline Erosive gastritis and erosive reflux esophagitis, $n(\%)$ \\
\hline Cardiovascular disease, $n(\%)$ \\
\hline Diabetes mellitus, $n(\%)$ \\
\hline Adenoma size, $\mathrm{cm}$ \\
\hline ¡PTH, $\mathrm{pg} / \mathrm{mL}(n=394)$ \\
\hline Serum total Ca, $\mathrm{mmol} / \mathrm{L}(n=205) 0$ \\
\hline Serum iCa, $\mathrm{mmol} / \mathrm{L}(n=370)$ \\
\hline Serum $\mathrm{P}, \mathrm{mmol} / \mathrm{L}(n=161)$ \\
\hline ALP, IU/L $(n=54)$ \\
\hline 24-h calciuria, $\mathrm{mmol} / 24 \mathrm{~h}(n=64)$ \\
\hline Creatinine, $\mathrm{mcmol} / \mathrm{L}(n=394)$ \\
\hline $\mathrm{GFR}^{* *}, \mathrm{~mL} / \mathrm{min} / 1.73 \mathrm{~m}^{2}(n=394)$ \\
\hline $25(\mathrm{OH}) \mathrm{D}, \mathrm{ng} / \mathrm{mL}(n=91)$ \\
\hline
\end{tabular}

\begin{tabular}{c}
\hline Values median $(25 ; 75$ quartile), $\%$ \\
\hline $60(53 ; 67)$ \\
$273(69.3 \%)$ \\
$371(94.2 \%)$ \\
$23(5.8 \%)$ \\
$28.4(25.6 ; 33.6)$ \\
$1.0(1.0 ; 3.0)$ \\
$190(48.2 \%)$ \\
$46(11.7 \%)$ \\
$7(1.8 \%)$ \\
$135(34.3 \%)$ \\
$68(17.1 \%)$ \\
$43(10.9 \%)$ \\
$33(8.4 \%)$ \\
$267(67.8 \%)$ \\
$48(12.2 \%)$ \\
$1.6(1.3 ; 2.5)$ \\
$190.5(133.3 ; 308.6)$ \\
$2.79(2.69 ; 2.92)$ \\
$1.49(1.41 ; 1.58)$ \\
$0.92(0.81 ; 1.09)$ \\
$96.6(71.0 ; 127.2)$ \\
$8.6(3.9 ; 10.8)$ \\
$75.5(65.6 ; 89.0)$ \\
$79(63 ; 91)$ \\
$14.8(9.4 ; 19.8)$ \\
\end{tabular}

\begin{tabular}{c}
\hline Normal range \\
\hline N/A \\
N/A \\
N/A
\end{tabular}

$18.5-24.9$

$\mathrm{N} / \mathrm{A}$

$N / A$

$\mathrm{N} / \mathrm{A}$

N/A

N/A

$\mathrm{N} / \mathrm{A}$

$N / A$

$\mathrm{N} / \mathrm{A}$

$\mathrm{N} / \mathrm{A}$

N/A

$\mathrm{N} / \mathrm{A}$

$15.0-65.0$

$2.15-2.65$

$1.11-1.32$

$0.81-1.45$

$<105.0$

2.5-8.0

$50.0-97.0$

$>90$

$30.0-100.0$

*Known duration of PHPT is a time between the first signs of PTPH and the surgery. ${ }^{* *}$ was calculated by MDRD formula.

25(OH)D, 25-hydroxyvitamin D; ALP, alkaline phosphatase; CPP, calcium-phosphorus product; CVD, cardiovascular disease; GFR, glomerular filtration rate; iCa, ionized calcium; iPTH, intact PTH; P, phosphorus; total Ca, total calcium.

asymptomatic patients (Table 2). However, osteoporosis was more frequent among symptomatic ones (56.8 and $37.0 \%, P=0.0001)$.

We did not find the difference in adenoma size and $25(\mathrm{OH}) \mathrm{D}$ level between the groups, but the symptomatic patients demonstrated higher iPTH level (202.9 and 181.0 $\mathrm{pg} / \mathrm{mL}, P=0.022)$. It should be noted that the subgroup who had $25(\mathrm{OH}) \mathrm{D}$ measurements represented only about $23 \%$ of the entire group. Serum 25(OH)D level was negatively correlated with PTH $(\mathrm{r}=-0.294, P=0.005)$, iCa $(\mathrm{r}=-0.268,=0.010)$ and total $\mathrm{Ca}(\mathrm{r}=-0.284, P=0.014)$ levels. All patients with known $25(\mathrm{OH}) \mathrm{D}$ level received vitamin D supplementation, but the vitamin $\mathrm{D}$ deficiency was compensated only in two patients before surgery.

Expected relationships between laboratory characteristics were noted between PTH and iCa $(\mathrm{r}=+0.450, P<0.0001)$; total $\mathrm{Ca}(\mathrm{r}=+0.377, P<0.0001)$; phosphorus level $(\mathrm{r}=-0.308, P<0.0001)$ and the ALP $(\mathrm{r}=+0.377, P=0.006)$. The 24 -h urinary calcium excretion was negatively associated with age $(\mathrm{r}=-0.561, P<0.0001)$, creatinine level $(\mathrm{r}=-0.314, P=0.022)$ and positively associated with GRF $(\mathrm{r}=+0.488, P=0.0002)$. Negative correlations between PTH and BMD values were found in lumbar spine $(\mathrm{r}=-0.291, P=0.011)$ and distal radius $(\mathrm{r}=-0.472, P=0.006)$. There was no significant correlation between PTH and T-score in proximal femur $(P=0.17)$.

Patients with symptomatic PHPT were subclassified into several groups depending on their clinical presentation (Table 3). More than a half of patients (50.9\%) had renal manifestations (nephrolithiasis or nephrocalcinosis); a smaller number but nevertheless noteworthy $26.1 \%$ had disorders of the gastrointestinal tract (GI) only (cholelithiasis - 29 cases, peptic ulcer disease -22 cases, erosive gastritis and esophagitis - 16 cases). Approximately $13 \%$ of patient had predominantly skeletal manifestations (fragility fractures or osteitis fibrosa cystica). The combination of skeletal, renal and GI involvement was seen in $9.5 \%$ of cases.

Results of analysis showed that patients with predominantly renal manifestations were younger than those with GI and skeletal manifestations (59, 62 and 64 years, respectively). In addition, we found differences in iPTH level (265.8 and $187.1 \mathrm{pg} / \mathrm{mL}$, respectively) between skeletal and GI subgroup patients.

Interestingly, manifestations of CVD were observed in a large number of patients constituting $67.7 \%$ (267) of the entire cohort. Among cardiovascular diseases we observed arterial hypertension in 252 cases,

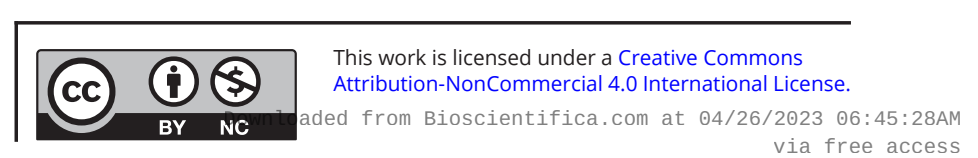


Table 2 Characteristics of symptomatic and asymptomatic PHPT patients.

\begin{tabular}{l}
\hline Parameters \\
\hline Age, years \\
Gender: female, $n$ (\%) \\
Male, $n(\%)$ \\
BMI, kg/m² \\
CVD, $n$ (\%) \\
Diabetes mellitus, $n$ (\%) \\
T-score, SD: L1-L4 \\
Femoral neck \\
1/3 Radius \\
Adenoma size, cm \\
Serum total Ca, $\mathrm{mmol} / \mathrm{L}$ \\
Serum iCa, $\mathrm{mmol} / \mathrm{L}$ \\
Serum P, mmol/L \\
ALP, IU/L \\
24-h urinary calcium, $\mathrm{mmol} / 24 \mathrm{~h}$ \\
GFR, $\mathrm{mL} / \mathrm{min} / 1.73 \mathrm{~m}^{2}$ \\
iPTH, pg/mL \\
25(OH)D, ng/mL
\end{tabular}

\begin{tabular}{c} 
Symptomatic PHPT, $\boldsymbol{n}=\mathbf{2 2 2}$ \\
\hline $60(53 ; 67)$ \\
$208(93.7 \%)$ \\
$13(6.3 \%)$ \\
$29.1(25.7 ; 35.0)$ \\
$157(70.7 \%)$ \\
$31(13.6 \%)$ \\
$-2.5(-3.2 ;-1.4), n=43$ \\
$-2.0(-2.4 ;-1.3), n=42$ \\
$-3.9(-4.2 ;-1.8), n=17$ \\
$1.7(1.2 ; 2.5)$ \\
$2.81(2.67 ; 2.96), n=117$ \\
$1.49(1.42 ; 1.58), n=214$ \\
$0.90(0.81 ; 1.07), n=89$ \\
$87.2(70.2 ; 132.0), n=32$ \\
$8.6(4.0 ; 10.8), n=37$ \\
$78(58 ; 91), n=222$ \\
$202.9(140.1 ; 352.9), n=222$ \\
$13.3(9.2 ; 16.9), n=52$
\end{tabular}

\begin{tabular}{clll}
\hline Asymptomatic PHPT, $\boldsymbol{n}=\mathbf{1 7 2}$ & & \multicolumn{1}{c}{$\boldsymbol{P}$} \\
\cline { 1 - 1 } $59(53 ; 66)$ & & 0.36 \\
$162(94.2 \%)$ & & 0.56 \\
$10(5.8 \%)$ & & \\
$27.9(25.1 ; 33.4)$ & & 0.50 \\
$109(63.4 \%)$ & & 0.076 \\
$16(9.3 \%)$ & & 0.16 \\
$-2.2(-2.8 ;-1.2), n=32$ & & 0.23 \\
$-1.5(-2.7 ;-0.8), n=30$ & & 0.47 \\
$-2.5(-3.6 ;-1.5), n=16$ & & 0.12 \\
$1.6(1.4 ; 2.2)$ & & 0.96 \\
$2.79(2.70 ; 2.90), n=88$ & & 0.55 \\
$1.49(1.40 ; 1.58), n=156$ & & 0.59 \\
$0.96(0.79 ; 1.09), n=72$ & & 0.74 \\
$99.3(79.6 ; 127.2), n=22$ & & 0.73 \\
$8.6(3.2 ; 9.8), n=27$ & & 0.73 \\
$81(67 ; 91), n=172$ & & 0.56 \\
$181.0(127.6 ; 246.7), n=172$ & & 0.022 \\
$15.4(10.9 ; 20.3), n=39$ & & 0.13
\end{tabular}

25(OH)D, 25-hydroxyvitamin D; ALP, alkaline phosphatase; CPP, calcium-phosphorus product; CVD, cardiovascular disease; GFR, glomerular filtration rate; iCa, ionized calcium; iPTH, intact PTH; P, phosphorus; total $\mathrm{Ca}$, total calcium.

angina pectoris in 41 cases, history of myocardial infarction in 15 cases, silent myocardial ischemia in 6 cases, cardiac conduction disturbances in 16 cases, cardiac rhythm disturbances in 37 cases, heart failure in 41 cases, acquired heart valve disease in 12 cases, and congenital heart valve disease in 6 cases. Seven patients underwent percutaneous transluminal coronary angioplasty, seven had a history of stroke and another two had a history of pulmonary embolism. Involvement of the cardiovascular system did not differ in symptomatic and asymptomatic subjects $(70.7 \%$ vs $63.4 \%, P=0.076)$. Both age and BMI were higher in patients with CVD, whether or not they were symptomatic (62 and 53 years, $P<0.0001 ; 30.4$ vs $26.0 \mathrm{~kg} / \mathrm{m}^{2}, P<0.0001$, respectively), compared with patients with PHPT and no CVD.

When it comes to surgery, we found that focused parathyroidectomy was performed in 289 cases, unilateral neck exploration was performed in 6 cases and bilateral neck exploration in 47 cases. Six patients underwent parathyroidectomy plus thyroidectomy and in 36 cases there were parathyroidectomy was accompanied by hemithyroidectomy. In three cases videothoracoscopy was performed. Analysis of the postoperative period revealed hypocalcemia, which required urgent use of calcium supplements and active form of vitamin $\mathrm{D}$, in $5.6 \%$ of patients. But in most cases hypocalcemia was transient. We did not find association between serum calcium level and the type of surgical approach. Of 90 interviewed patients who underwent parathyroidectomy, only four patients had permanent postoperative hypoparathyroidism, requiring constant intake of calcium and vitamin D supplementation. Three of these patients underwent bilateral neck exploration and in one case parathyroidectomy plus hemithyroidectomy was performed.

\section{Discussion}

In this report, we provide new information from a large cohort of 394 PHPT patients from three major medical Centers in Saint-Petersburg, Russia covering the period from 2011 to 2018. Because of the large cohort size, our experience has enabled a demographic analysis and comparison of the different clinical presentations. Of interest, since virtually all of these patients met at least one criterion for surgery, whether they were symptomatic or not, the data are specifically relevant for patients meeting surgical guidelines.

In our study females predominated to a greater extent in contrast to other studies $(5,13,15)$. Of note, based on the current Russian PHPT register, from a total of 1914 patients there are only 178 men (9.3\%) with a F:M ratio close to 9.8:1. But for patients around the age of 50 years the F:M ratio was $16: 1$, which is consistent with our research (16). This could be explained by the general demographic features in the country from one hand, and the passive attitude of men when it comes to seeking medical care from the other hand. The average age of the patient population was 60 years, consistent

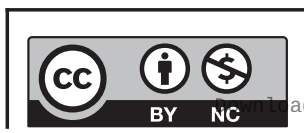

This work is licensed under a Creative Commons Attribution-NonCommercial 4.0 International License. ded from Bioscientifica.com at 04/26/2023 06:45:28AM via free access 
Table 3 Comparative characteristics of patients with symptomatic form of PHPT $(n=201)$.

\begin{tabular}{|c|c|c|c|c|}
\hline & $\begin{array}{l}\text { Skeletal manifestation, } \\
\qquad n=30\end{array}$ & $\begin{array}{c}\text { Renal manifestation } \\
\text { (nephrolithiasis/ } \\
\text { nephrocalcinosis), } \boldsymbol{n}=\mathbf{1 1 3}\end{array}$ & $\begin{array}{c}\text { Gastrointestinal } \\
\text { manifestation, } n=58\end{array}$ & \\
\hline Parameter & 1 & 2 & 3 & $\boldsymbol{P}$ \\
\hline Age, years & $64(54 ; 69)$ & $59(51 ; 66)$ & $62(56 ; 69)$ & 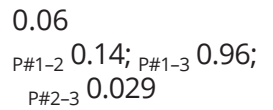 \\
\hline Gender: female, $n(\%)$ & $30(100 \%)$ & $102(90.3 \%)$ & $57(98.3 \%)$ & 0.037 \\
\hline Male, $n(\%)$ & 0 & $11(9.7 \%)$ & $1(1.7 \%)$ & \\
\hline $\mathrm{BMI}, \mathrm{kg} / \mathrm{m}^{2}$ & $27.6(24.4 ; 30.8)$ & $28.7(25.6 ; 33.4)$ & $32.5(26.1 ; 39.5)$ & 0.15 \\
\hline CVD, $n(\%)$ & $22(73.3 \%)$ & $74(64.6 \%)$ & $47(81.0 \%)$ & $\begin{array}{l}0.078 \\
\text { P\#1-2 0.28; }{ }_{\text {P\#1-3 } 0.28 ;} \text { P\#2-3 } 0.05\end{array}$ \\
\hline Diabetes mellitus, $n(\%)$ & $5(16.7 \%)$ & $15(13.3 \%)$ & $7(12.1 \%)$ & 0.89 \\
\hline T-score, SD L1-L4 & $-2.9(-3.9 ;-1.9), n=7$ & $-2.5(-3.3 ;-1.6), n=22$ & $-1.9(-2.6 ;-0.9), n=7$ & 0.34 \\
\hline Neck & $-2.1(-2.8 ;-1.6), n=7$ & $-2.3(-2.7 ;-1.9), n=18$ & $-1.5(-1.8 ;-1.08), n=9$ & 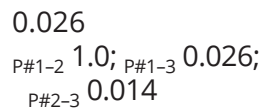 \\
\hline 1/3 Radius & $-4.5(-4.5 ;-4.5), n=2$ & $-4.0(-4.8 ;-1.8), n=8$ & $-3.0(\mathrm{~N} / \mathrm{A}), n=1$ & 0.45 \\
\hline Adenoma size, cm & $1.5(1.3 ; 2.1)$ & $1.8(1.2 ; 2.5)$ & $1.6(1.2 ; 2.0)$ & 0.69 \\
\hline Serum total Ca, mmol/L & $2.78(2.66 ; 2.92), n=20$ & $2.88(2.70 ; 3.01), n=55$ & $2.77(2.67 ; 2.82), n=27$ & 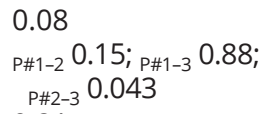 \\
\hline Serum iCa, mmol/L & $1.48(1.41 ; 1.55), n=29$ & $1.52(1.43 ; 1.61), n=108$ & $1.49(1.41 ; 1.59), n=57$ & 0.21 \\
\hline Serum $\mathrm{P}, \mathrm{mmol} / \mathrm{L}$ & $0.92(0.87 ; 1.04), n=14$ & $0.90(0.80 ; 1.08), n=44$ & $0.88(0.76 ; 0.98), n=20$ & 0.69 \\
\hline$A L P, I U / L$ & $132.0(87.9 ; 249.2), n=5$ & $87.2(70.4 ; 109.3), n=13$ & $82.2(61.0 ; 134), n=7$ & 0.43 \\
\hline 24-h calciuria, mmol/24 h & $6.2(2.7 ; 9.0), n=3$ & $8.8(4.6 ; 10.8), n=19$ & $9.2(8.1 ; 11.9), n=8$ & 0.21 \\
\hline GFR, mL/min/1.73m² & $95(66 ; 111), n=29$ & $78(58 ; 91), n=113$ & $75(46 ; 91), n=58$ & 0.25 \\
\hline iPTH, pg/mL & $265.8(176.2 ; 443.8), n=29$ & $205.9(146.7 ; 364.0), n=113$ & $187.1(125.7 ; 259.0), n=21$ & $\begin{array}{l}0.031 \\
\begin{array}{l}\text { P\#1-2 } 0.10 ; \\
P_{\# 2-3} 0.11\end{array}\end{array}$ \\
\hline 25(OH)D, ng/mL & $11.1(9.2 ; 16.3), n=10$ & $14.9(10.2 ; 27.2), n=22$ & $12.8(8.0 ; 16.7), n=14$ & 0.38 \\
\hline
\end{tabular}

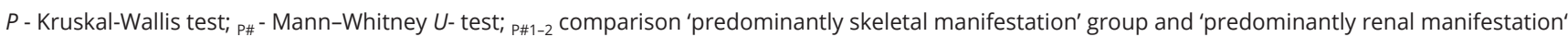

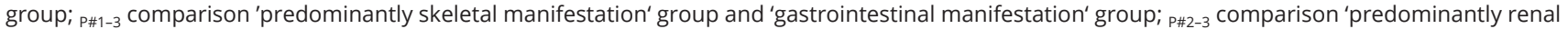
manifestation' group and gastrointestinal manifestation' group.

25(OH)D, 25-hydroxyvitamin D; ALP, alkaline phosphatase; CPP, calcium-phosphorus product; CVD, cardiovascular disease; GFR, glomerular filtration rate; iCa, ionized calcium; iPTH, intact PTH; P, phosphorus; total Ca, total calcium.

with most observations that this disease surfaces most commonly in the 1 st decade after menopause $(5,15)$. As the study results showed, symptomatic PHPT remains the dominant form in Russia and other developing countries, where measuring of serum calcium level is not included in routine screening. SK Bhadada and colleagues reported 95\% symptomatic subjects among a cohort of 464 patients (17). While VJ Mallikarjuna and colleagues reported only $38 \%$ of asymptomatic subjects of their 54 patients (18). More than 55\% of patients in our study had symptomatic PHPT with classical skeletal and renal manifestations. Consequently, skeletal involvement was more common in females while the frequency of other manifestations was the same independently of gender. L Meng and colleagues compared patients from USA and China and found that female PHPT patients might be more sensitive to bone loss and that male patients might be more likely to develop renal disease (19). Osteitis cystica fibrosa is a rare skeletal PHPT manifestations nowadays. It is found in $2-3 \%$ of PHPT patients $(20,21)$. Brown tumors commonly affect pelvic bones, femur, tibia, ribs or clavicles. In our study only six patients (1.5\%) had brown tumors with the most frequent localization in pelvic bones, and all of them had renal or gastrointestinal disorders.

Gastrointestinal manifestation is not so common as skeletal or renal disturbances (22). It includes peptic ulcer disease, pancreatitis, gallstone disease, erosive lesions of upper GI tract. But most of patients have any common GI complains, such as abdominal pain, nausea, constipation, heartburn or loss of appetite. Gallstone disease is more common in women compared to men, and the risk of its occurrence increases with age. The prevalence of cholelithiasis varies near $10-30 \%$ of population (23). In our study $17.1 \%$ of patients had gall stones and there was no difference between men and women. But the frequency of gall stones was higher in patients older than 55 years

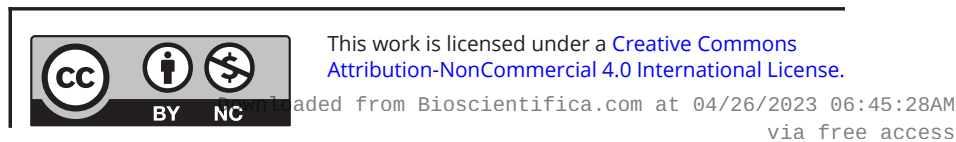


compared to younger ones $(14.8 \% \& 2.3 \%, P=0.007)$ as it is in common population.

Pancreatitis is not uncommon complication of PHPT, however, in few countries, such as India, where symptomatic form is more common, pancreatitis is reported in 10-20\% of PHPT patients (23). In our study 57 patients had sings of chronic pancreatitis in their medical records and $12.8 \%$ of them were symptomatic, which is consistent with the data in other (24). However, we exclude the possibility that pancreatitis was a comorbid disease in these patients and just in one case (young woman) we have confirmation that pancreatic calculi were associated with PHPT.

Of great interest is the widespread prevalence of CVD manifestations among our symptomatic and asymptomatic subjects. Approximately $65 \%$ of patients in both groups had one or more cardiovascular diseases. Mechanisms to account for these observations continue to be speculative, including direct effects of PTH on the vascular endothelium and cardiomyocytes $(25,26,27)$. Vitamin D deficiency may also be etiologic in these patients who demonstrate CV involvement (28). There are some studies that demonstrated the relationship of cardiovascular morbidity with iPTH level $(29,30)$. Han et al. (31) identified the prevalence of CV risk factors in patients with PHPT, especially in men, compared to the general population in New Jersey. It is known that male gender is a risk factor for CAD. In general, Russian population men are affected with CAD in three times more than women. According to Russian statistic agency the incidence of CAD in 2018 was 308.7 per 100,000 and mortality from CAD in men was much higher than in women (322.5 and 296.8 per 100,000, respectively) (32). In our study of 28 men five subjects (17.9\%) had CAD and there was no difference between females and males.

This experience adds an important dimension to the international demographics of PHPT, emphasizing how the clinical presentations of this disease will vary according to the referral patterns, standard evaluation procedures, and the prevalence of vitamin D deficiency.

\section{Limitations}

The limitations of this study are its retrospective nature and absence of a direct contact with patients. All data were collected only from medical histories, including the diagnoses and results of molecular-genetic tests. Infrequent assessment of both serum 25(OH)D level and the need of vitamin D deficiency compensation before surgery, does not allow us to finally rule out secondary PHPT in all cases. Infrequent measurement of 24-h urinary calcium and lack of determination of calcium-creatinine ratio in urine does not allow us to rule out familial hypocalciuric hypercalcemia. Also, infrequent measurement of both total and ionized calcium, phosphorus, alkaline phosphatase, lack of the DXA results in some medical histories, lack of the results of the abdominal ultrasound did not allow us to fully describe the differences between the clinical forms of the disease.

Keeping those limitations in mind, we think that it is necessary to conduct further multicenter prospective studies to assess not just serum 25(OH)D level, but other relevant biochemical parameters as well, in patients with a possible diagnosis of PHPT to have a better understanding of the clinical manifestations.

\section{Declaration of interest}

The authors declare that there is no conflict of interest that could be perceived as prejudicing the impartiality of the research reported.

\section{Funding}

This research was financially supported by the Ministry of Science and Higher Education of the Russian Federation (Agreement No. 075-152020-901).

\section{Acknowledgement}

The authors would like to express their gratitude to Vladislav Solntsev for help in the statistical analysis.

\section{References}

1 Bilezikian JP, Cusano NE, Khan AA, Liu JM, Marcocci C \& Bandeira F. Primary hyperparathyroidism. Nature Reviews: Disease Primers 20162 16033. (https://doi.org/10.1038/nrdp.2016.33)

2 Bilezikian JP. Primary hyperparathyroidism. Journal of Clinical Endocrinology and Metabolism 2018103 3993-4004. (https://doi. org/10.1210/jc.2018-01225)

3 Fraser WD. Hyperparathyroidism. Lancet 2009374 145-158. (https:// doi.org/10.1016/S0140-6736(09)60507-9)

4 AACE/AAES Task Force on Primary Hyperparathyroidism. The American Association of Clinical Endocrinologists and the American Association of Endocrine Surgeons position statement on the diagnosis and management of primary hyperparathyroidism. Endocrine Practice 200511 49-54. (https://doi.org/10.4158/ EP.11.1.49)

5 Dedov II, Melnichenko GA, Mokrysheva NG, Rozhinskaya LY, Kusnezov NS, Pigarova EA, Voronkova IA, Lipatenkova AK, Egshatyan LV, Mamedova EO, et al. Primary hyperparathyroidism: the clinical picture, diagnostics, differential diagnostics, and methods of treatment. Problemy Endocrinologii 201662 40-77. (https://doi.org/10.14341/probl201662640-77)

6 Roizen J \& Levine MA. Primary hyperparathyroidism in children and adolescents. Journal of the Chinese Medical Association 201275 425-434. (https://doi.org/10.1016/j.jcma.2012.06.012) 
7 Gasser RW. Clinical aspects of primary hyperparathyroidism: clinical manifestations, diagnosis, and therapy. Wiener Medizinische Wochenschrift 2013163 397-402. (https://doi.org/10.1007/s10354013-0235-z)

8 Wermers RA, Khosla S, Atkinson EJ, Achenbach SJ, Oberg AL, Grant CS \& Melton 3rd LJ. Incidence of primary hyperparathyroidism in Rochester, Minnesota, 1993-2001: an update on the changing epidemiology of the disease. Journal of Bone and Mineral Research 2006 21 171-177. (https://doi.org/10.1359/JBMR.050910)

9 Ferraz-de-Souza B. The evolution of primary hyperparathyroidism. Archives of Endocrinology and Metabolism 201559 381-382. (https:// doi.org/10.1590/2359-3997000000124)

10 Bilezikian JP, Bandeira L, Khan A \& Cusano NE. Hyperparathyroidism. Lancet 2018391 168-178. (https://doi. org/10.1016/S0140-6736(17)31430-7)

11 Cobbeta S. Normocalcemic hyperparathyroidism. Frontiers of Hormone Research 201951 23-39. (https://doi.org/10.1159/000491036)

12 Schini M, Jacques RM, Oakes E, Peel NFA, Walsh JS \& Eastell R. Normocalcemic hyperparathyroidism: study of its prevalence and natural history. Journal of Clinical Endocrinology and Metabolism 2020 105 e1171-e1186. (https://doi.org/10.1210/clinem/dgaa084)

13 Bilezikian JP, Brandi ML, Eastell R, Silverberg SJ, Udelsman R, Marcocci C \& Potts Jr JT. Guidelines for the management of asymptomatic primary hyperparathyroidism: summary statement from the fourth international workshop. Journal of Clinical Endocrinology and Metabolism 201499 3561-3569. (https://doi. org/10.1210/jc.2014-1413)

14 Mokrysheva NG, Rozhinskaya LY, Peretokina EV, Rostomyan LG, Mirnaya SS, Pronin VS, Markina NV, Shebesheva EN, Antsiferov MB $\&$ Dedov II. The results of analysis of the major epidemiological characteristics of primary hyperparathyroidism in Russia based on the registry data. Problemy Endocrinologii 201258 16-20. (https://doi. org/10.14341/probl201258516-20)

15 Wilhelm SM, Wang TS, Ruan DT, Lee JA, Asa SL, Duh QY, Doherty GM, Herrera MF, Pasieka JL, Perrier ND, et al. The American Association of Endocrine Surgeons Guidelines for definitive management of primary hyperparathyroidism. JAMA Surgery 2016 151 959-968. (https://doi.org/10.1001/jamasurg.2016.2310)

16 Mokrysheva NG, Mirnaya SS, Dobreva EA, Maganeva IS, Kovaleva EV, Krupinova JA, Kryukova IV, Tevosyan LKh, Lukyanov SV, Markina NV, et al. Primary hyperparathyroidism in Russia according to the registry. Problems of Endocrinology 201965 300-310. (https:// doi.org/10.14341/probl9946)

17 Bhadada SK, Arya AK, Mukhopadhyay S, Khadgawat R, Sukumar S, Lodha S, Singh DN, Sathya A, Singh P \& Bhansali A. Primary hyperparathyroidism: insights from the Indian PHPT registry. Journal of Bone and Mineral Metabolism 201836 238-245. (https://doi. org/10.1007/s00774-017-0833-8)

18 Mallikarjuna VJ, Mathew V, Ayyar V, Bantwal G, Ganesh V, George B, Hemanth GN \& Vinotha P. Five-year retrospective study on primary hyperparathyroidism in South India: emerging roles of minimally invasive parathyroidectomy and preoperative localization with methionine positron emission tomography-computed tomography scan. Indian Journal of Endocrinology and Metabolism 201822 355-361. (https://doi.org/10.4103/ijem.IJEM_445_16)

19 Meng L, Liu S, Al-Dayyeni A, Sheng Z, Zhou Z \& Wang X. Comparison of initial clinical presentations between primary hyperparathyroidism patients from New Brunswick and Changsha. International Journal of Endocrinology 2018 6282687. (https://doi. org/10.1155/2018/6282687)

20 Grégoire C, Soussan M, Dumuis ML, Naggara N, Martin A, Dhote R, Audard V, Neuman A \& Weinmann P. Contribution of multimodality imaging for positive and aetiological diagnosis of multiple brown tumours. Annales d'Endocrinologie 201273 43-50. (https://doi. org/10.1016/j.ando.2011.10.002)

21 Oliveira FM, Makimoto TE, Scalissi NM, Marone MM \& Maeda SS Regression of orbital brown tumor after surgical removal of parathyroid adenoma. Archives of Endocrinology and Metabolism 2015 59 455-459. (https://doi.org/10.1590/2359-3997000000088)

22 Minisola S, Gianotti L, Bhadada S \& Silverberg SJ. Classical complications of primary hyperparathyroidism. Best Practice and Research: Clinical Endocrinology and Metabolism 201832 791-803. (https://doi.org/10.1016/j.beem.2018.09.001)

23 Lindstrom CG. Frequency of gallstone disease in a well-defined Swedish population: a prospective necropsy study in Malmö. Scandinavian Journal of Gastroenterology 197712 341-346. (https:// doi.org/10.3109/00365527709180938)

24 Arya AK, Bhadada SK, Mukherjee S, Singh P, Rana SS, Dahiya D, Sood A, Saikia UN, Prakash M, Bhasin DK, et al. Frequency and predictors of pancreatitis in symptomatic primary hyperparathyroidism. Indian Journal of Medical Research 2018148 721-727. (https://doi.org/10.4103/ijmr.IJMR_353_16)

25 Pepe J, Cipriani C, Sonato C, Raimo O, Biamonte F \& Minisola S. Cardiovascular manifestations of primary hyperparathyroidism: a narrative review. European Journal of Endocrinology $2017 \mathbf{1 7 7}$ R297-R308. (https://doi.org/10.1530/EJE-17-0485)

26 Walker MD \& Silverberg SJ. Primary hyperparathyroidism. Nature Reviews: Endocrinology 201814 115-125. (https://doi.org/10.1038/ nrendo.2017.104)

27 McMahon DJ, Carrelli A, Palmeri N, Zhang C, DiTullio M, Silverberg SJ \& Walker MD. Effect of parathyroidectomy upon left ventricular mass in primary hyperparathyroidism: a meta-analysis. Journal of Clinical Endocrinology and Metabolism 2015100 4399-4407. (https://doi.org/10.1210/jc.2015-3202)

28 Lotito A, Teramoto M, Cheung M, Becker K \& Sukumar D. Serum parathyroid hormone responses to vitamin D supplementation in overweight/obese adults: a systematic review and meta-analysis of randomized clinical trials. Nutrients 20179 241. (https://doi. org/10.3390/nu9030241)

29 Pilz S, Tomaschitz A, Drechsler C, Rotz E, Boehm BO, Grammer TB \& Marz W. Parathyroid hormone level is associated with mortality and cardiovascular events in patients undergoing coronary angiography. European Heart Journal 201031 1591-1598. (https://doi.org/10.1093/ eurheartj/ehq109)

30 Kamycheva E, Sundsfjord J \& Jorde R. Serum parathyroid hormone levels predict coronary heart disease: the Tromsø Study. European Journal of Cardiovascular Prevention and Rehabilitation 200411 69-74. (https://doi.org/10.1097/01.hjr.0000114706.27531.01)

31 Han D, Trooskin S \& Wang X. Prevalence of cardiovascular risk factors in male and female patients with primary hyperparathyroidism. Journal of Endocrinological Investigation 201235 548-552. (https://doi.org/10.3275/7861)

32 Federal Service of State statistics (Rosstat). Demographic yearbook of Russia 2019. Statistical Collection. Moscow, 2019.

Received in final form 7 December 2020

Accepted 5 January 2021

Accepted Manuscript published online 9 January 2021 https://ec.bioscientifica.com https://doi.org/10.1530/EC-20-0515 (c) 2021 The authors Published by Bioscientifica Ltd

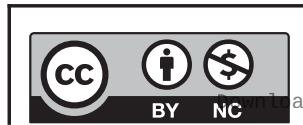

This work is licensed under a Creative Commons Attribution-NonCommercial 4.0 International License. ded from Bioscientifica.com at $04 / 26 / 2023$ 06:45:28AM 